\title{
HUBUNGAN ANTARA OBESITAS DENGAN KEJADIAN OSTEOARTHRITIS SENDI LUTUTDI RSU TEUNGKU PEUKAN ACEH BARAT DAYA
}

\author{
Zurrahmi Sofyan ${ }^{1}$, Fakhrul Rizal ${ }^{2}$ \\ ${ }^{1}$ Mahasiswa Fakultas Kedokteran, Universitas Abulyatama,Aceh,Indonesia \\ ${ }^{2}$ Dosen Fakultas Kedokteran, Universitas Abulyatama,Aceh,Indonesia
}

\begin{abstract}
Relationship between Obesity and the incidence of osteoarthritis of the knee joint in Teungku Peukan Hospital, Southwest Aceh. Osteoarthritis (OA) or progressive degenerative joint disease is chronic which usually occurs in people between early adulthood and old age characterized by joint cartilage damage. Osteoarthritis has modifiable risk factors including obesity. The person with obesity or overweight three times increases the risk of OA at knee. Obesity is BMI/IMT ranging from 30 to $>40 \mathrm{~kg} / \mathrm{m} 2$. This study aims to determine the relationship between obesity and the incidence of knee joint osteoarthritis in Teungku Peukan Hospital, Southwest Aceh. The method used by this research was a quantitative research with cross sectional study approach design. The population of this study were all OA knee patients with obesity. The sample of this study was totally 70 people who had the certain criteria; the inclusion and exclusion criteria with non-probability sampling techniques. Retrieval of data using questionnaires, interviews and measuring weight and height. Data analysisused a chi-square test at a significance level of $95 \%(P<0.05)$. The results of statistical tests in this study using the chi square test were obtained $P$ value $=0.000(P<0.05)$ which showed a relationship between obesity and the incidence of osteoarthritis (OA) of the knee in poly-surgery, poly-nerve and internal medicine at Teungku Peukan Hospital in Southwest Aceh.
\end{abstract}

Keywords: Osteoarthritis, Obesity, Knee Joint, Quantitative, Chi-Square.

\begin{abstract}
Abstrak: Hubungan antara Obesitas dengan kejadian Osteoartritis sendi lutut di RSU Teungku Peukan Aceh Barat Daya.Osteoarthritis (OA) atau penyakit sendi degeneratif yang progresif bersifat kronik dan biasanya terjadi pada usia pertengahan hingga usia lanjut ditandai dengan adanya kerusakan kartilago sendi. Osteoartritis memiliki faktor risiko yang dapat dimodifikasi yaitu obesitas, seseorang dengan obesitas atau overweight tiga kali berisikoterkena OA lutut. Obesitas yaitu BMI/IMT mulai dari 30 hingga $>40 \mathrm{~kg} / \mathrm{m}^{2}$. Penelitian ini bertujuan untuk mengetahui Hubungan antara Obesitas dengan kejadian Osteoartritis Sendi Lutut di RSUD Teungku Peukan Aceh Barat Daya. Jenis penelitian ini adalah metode penelitian kuantitatif dengan desain pendekatan studi cross sectional. Populasi pada penelitian ini adalah seluruh pasien OA lutut dengan Obesitas. Sampel pada penelitian ini berjumlah 70 orang yang diambil memenuhi kriteria inklusi dan kriteria eksklusi dengan teknik Non Probability sampling. Pengambilan data dengan menggunakan kuesioner, wawancara serta mengukur berat badan dan tinggi badan. Analisis data menggunakan uji chi-square pada tingkat kemaknaan $95 \%$ $(\mathrm{P}<0,05)$. Hasil uji statistik pada penelitian ini dengan menggunakan uji chi square test didapatkan $P$ value $=0,000(P<0,05)$ yang berarti terdapat hubungan yang bermakna antara obesitas dengan kejadian Osteoartritis (OA) lutut pada poli Bedah, poli Saraf dan poli Penyakit Dalam di RSUD Teungku Peukan Aceh Barat Daya.
\end{abstract}

Kata Kunci : Osteoartritis, Obesitas, Sendi Lutut, Kuantitatif, Chi-Square. 


\section{PENDAHULUAN}

Osteoartritis (OA) merupakan penyakit sendi degeneratif yang progresif bersifat Kronik dan biasanya terjadi pada usia pertengahan hingga lanjut usia ditandai dengan adanya kerusakan kartilago sendi (Kasim dkk, 2015). Dulay dkk (2015) menyebutkan bahwa osteoartritis dapat terkena di sendi mana pun, akan tetapi yang paling sering terkena yaitu sendi Lutut, pinggul, tangan, tulang belakang, dan kaki. Di mana gejala klinis utama dari OA adalah nyeri, kekakuan, keterbatasan gerak dan cacat fungsional.

Osteoartritis merupakan penyakit yang paling banyak ditemukan di dunia, termasuk di Indonesia. Menurut World Health Organization pada tahun 2007, OA adalah penyebab utama penyakit kecacatan kronis di dunia. Penderita osteoartritis di dunia mencapai 151,4 juta jiwa (Ali, 2014). Mobasheri dan Batt (2016) dalam penelitiannya menyebutkan prevalensi OA dilaporkan sangat meningkat pada usia di atas 60 tahun dengan peningkatan obesitas di seluruh dunia. Menurut Buttgereit dkk (2014), secara global, OA lutut dan OA pinggul menempati peringkat ke-11 tertinggi di dunia yang dapat mengganggu aktivitas sehari-hari.

Berdasarkan penelitian yang dilakukan oleh Mutia Chanza Fauzi di RSUD dr.Zainoel Abidin Banda Aceh pada Tahun 2018, didapatkan bahwa osteoartritis lebih banyak didapatkan pada usia 51-60 tahun (34,3\%), berdasarkan jenis kelamin terbanyak pada perempuan $(61,4 \%)$, yang pernah mengalami cedera sendi sebanyak $(71,4 \%)$ responden, berdasarkan IMT terbanyak pada obesitas $(57,1 \%)$. Sedangkan pada penelitian yang dilakukan oleh Rizky Dahliyani Putri di RSUD Meuraxa, didapatkan prevalensi osteoarthritis sendi lutut yakni 50,0\% di mana yang lebih dominan yang mempunyai Indeks massa tubuh Obesitas. Osteoartritis lutut khusus nya di Aceh pada wilayah-wilayah aceh lainnya secara spesifiknya belum terdapat adanya data OA lutut yang pasti untuk mengetahui berapakah prevalensinya.

Faktor yang meningkatkan resiko dari penyakit Osteoartritis terdapat dua pembagian yaitu faktor predisposisi dan faktor biomekanis. Di mana faktor resiko yang paling umum yaitu usia, jenis kelamin, Obesitas dan genetik. Obesitas telah banyak dibuktikan bahwasanya menjadi faktor risiko $\mathrm{OA}$ lutut utama yang dapat dimodifikasi. Seseorang dengan Obesitas atau overweight tiga kali berisiko terkena OA lutut dibandingkan orang dengan berat badan Normal. Hasil studi Framingham menunjukkan wanita yang mengalami penurunan berat badan sebesar $5 \mathrm{~kg}$ dapat mengurangi risiko sebesar $50 \%$ terkena OA lutut. Studi yang sama juga menunjukkan pengurangan berat badan sangat berhubungan erat dengan pengurangan risiko dan progresifitas dari OA (Kulkarni dkk, 2016).

Menurut WHO (2018), obesitas yaitu BMI/IMT mulai dari 30 hingga $>40 \mathrm{~kg} /$ $\mathrm{m}^{2}$, telah mencapai proporsi epidemiologi di seluruh dunia. Obesitas dan overweight merupakan salah satu faktor yang berperan dalam terjadinya OA, terutama OA genu. Obesitas juga merupakan penyakit multifaktorial, terjadi karena adanya akumulasi jaringan lemak berlebihan, maka dari itu obesitas sangat mengganggu kesehatan. Obesitas terjadi dikarenakan sel lemak bertambah besar dan jumlahnya bertambah banyak, sehingga berat badan seseorang meningkat (Sugono, 2014).

Sugono (2014) dalam Buku Ajar Ilmu Penyakit Dalam menyatakan bahwa obesitas merupakan masalah kesehatan yang susah diatasi. Diperkirakan $\geq 250$ juta orang di seluruh dunia mempunyai IMT $30 \mathrm{~kg} / \mathrm{m}^{2}$, dimana sekitar $7 \%$ dari populasi orang dewasa di dunia. Angka obesitas tertinggi di Dunia berada di kepulauan Pasifik pada populasi Melanesia, Polinesia dan Mikronesia. Pada daerah Urban samoa diperkirakan $75 \%$ perempuan dan $60 \%$ laki-laki diklasifikasi sebagai obesitas.

Menurut hasil dari Riskesdas (2007) Provinsi Nanggroe Aceh Darussalam 
yang mengalami Obesitas sentral pada perempuan lebih tinggi dibandingkan pada laki-laki. Prevalensi di Aceh yang mengalami obesitas sudah terlihat sangat tinggi mencapai 16\%. Dari 21 Kabupaten/kota di Aceh, 7 di antaranya memiliki masalah obesitas mencapai $10 \%$ yaitu di kabupaten Aceh Singkil, Aceh Selatan, Aceh Tengah, Bener Meriah, Banda Aceh dan Lhokseumawe.

Berdasarkan penjelasan di atas, maka peneliti tertarik untuk membuat penelitian tentang Hubungan antara Obesitas dan kejadian Osteartritis sendi lutut di poliklinik RSU Teungku Peukan Aceh Barat Daya. Tujuan dari penelitian ini adalah untuk mengetahui hubungan antara obesitas dengan kejadian osteoartritis sendi lutut di RSU Teungku Peukan Aceh Barat Daya.

\section{METODE}

Jenis penelitian yang digunakan dalam penelitian ini adalah metode penelitian kuantitatif dengan desain pendekatan studi cross sectional. Populasi pada penelitian ini adalah seluruh pasien Osteoartritis lutut dan Obesitas yang berobat di poli Bedah, poli Saraf dan poli Penyakit Dalam RSU Teungku Peukan Aceh Barat Daya dari tanggal 22 Mei 2020 - 17 juni 2020. Sampel pada penelitian ini adalah pasien yang telah memenuhi kriteria Inklusi. Adapun kriteria inklusi pada penelitian ini adalah pasien yang terdiagnosa dan tidak terdiagnosa osteoartritis lutut dan obesitas yang bersedia mengikuti penelitian, pasien yang terdiagnosa osteoartritis lutut disertai Obesitas dan tidak obesitas, pasien yang tidak terdiagnosa osteoartritis lutut disertai obesitas dan tidak obesitas, dan pasien osteoartritis lutut dan obesitas yang berusia $>16$ Tahun. Teknik pengambilan sampel yang digunakan adalah Non Probability Sampling dengan Metode purposive Sampling yaitu suatu metode pengambilan sampel yang dilakukan dengan mengambil kasus atau responden yang yang memenuhi kriteria inklusi dan bersedia pada saat penelitian. Jumlah responden pada penelitian ini adalah 70 responden. Adapun variabel dependen dalam penelitian ini adalah Osteoartritis lutut dan variabel dependen adalah obesitas.

\section{HASIL}

\section{Analisis Univariat}

\section{Usia}

Tabel 1.Distribusi Frekuensi Berdasarkan Usia

\begin{tabular}{ccc}
\hline Usia & Frekuensi (n) & Persentase (\%) \\
\hline $21-30$ & $\mathbf{2}$ & $\mathbf{2 , 9}$ \\
$31-40$ & $\mathbf{7}$ & $\mathbf{1 0 , 0}$ \\
$41-50$ & $\mathbf{1 6}$ & $\mathbf{2 2 , 9}$ \\
$51-60$ & $\mathbf{2 0}$ & $\mathbf{2 8 , 6}$ \\
$61-70$ & $\mathbf{1 9}$ & $\mathbf{2 7 , 1}$ \\
$71-80$ & $\mathbf{6}$ & $\mathbf{8 , 6}$ \\
\hline Total & $\mathbf{7 0}$ & $\mathbf{1 0 0 , 0}$ \\
\hline
\end{tabular}

Berdasarkan tabel di atas dapat dilihat bahwa responden yang paling banyak adalah responden dengan usia 51-60 tahun yaitu sebanyak 20 orang
$(28,6 \%)$ dan yang paling sedikit usia 21-30 tahun yaitu sebanyak 2 orang $(2,9 \%)$.

\section{Jenis Kelamin}

Tabel 2.Distribusi Frekuensi Berdasarkan Jenis Kelamin

\begin{tabular}{ccc}
\hline Jenis Kelamin & Frekuensi (n) & Persentase (\%) \\
\hline Perempuan & 51 & 72,9 \\
Laki-Laki & 19 & 27,1 \\
\hline Total & 70 & 100,0
\end{tabular}


Berdasarkan tabel di atas dapat dilihat bahwa responden dengan jenis kelamin perempuan sebanyak 51 orang
$(72,9 \%)$ dan responden dengan jenis kelamin laki-laki sebanyak 19 orang $(27,1 \%)$.

\section{Indeks Masa Tubuh (IMT)}

Tabel 3.Distribusi Frekuensi Berdasarkan Indeks Massa Tubuh (IMT)

\begin{tabular}{ccc}
\hline Indeks Masa Tubuh (IMT) & Frekuensi (n) & Persentase (\%) \\
\hline Tidak Obesitas & 26 & 37,1 \\
Obesitas & 44 & 62,9 \\
\hline Total & 70 & 100,0 \\
\hline
\end{tabular}

Berdasarkan tabel di atas dapat dilihat bahwa responden dengan IMT tidak obesitas sebanyak 26 orang
$(37,1 \%)$ dan responden dengan IMT Obesitas sebanyak 44 orang $(62,9 \%)$.

\section{OsteoartritisLutut (OA)}

Tabel 4.Distribusi Frekuensi Berdasarkan Osteoartritis Lutut (OA)

\begin{tabular}{ccc}
\hline Osteoartritis Lutut (OA) & Frekuensi (n) & Persentase (\%) \\
\hline Ringan & $\mathbf{2 0}$ & $\mathbf{2 8 , 6}$ \\
Berat & 50 & $\mathbf{7 1 , 4}$ \\
\hline Total & $\mathbf{7 0}$ & $\mathbf{1 0 0 , 0}$ \\
\hline
\end{tabular}

Berdasarkan tabel di atas dapat dilihat bahwa responden dengan $\mathrm{OA}$ berat sebanyak 20 orang $(28,6 \%)$ dan responden dengan $\mathrm{OA}$ sangat berat sebanyak 50 orang $(71,4 \%)$.

\section{Analisis Bivariat}

Hubungan Obesitas Dengan Kejadian Osteoartritis Sendi Lutut Dengan Menggunakan IMT Dan Indeks Lequesne

Tabel 5. Hubungan antara Obesitas dengan Kejadian Osteoartritis Lutut (OA)

\begin{tabular}{|c|c|c|c|c|c|c|c|}
\hline \multirow{3}{*}{ IMT } & \multicolumn{4}{|c|}{ Osteoartritis Lutut } & \multirow{2}{*}{\multicolumn{2}{|c|}{ Total }} & \multirow{3}{*}{ P value } \\
\hline & \multicolumn{2}{|c|}{ Ringan } & \multicolumn{2}{|c|}{ Berat } & & & \\
\hline & $\mathbf{N}$ & $\%$ & $\mathbf{N}$ & $\%$ & $\mathbf{N}$ & $\%$ & \\
\hline Tidak obesitas & 15 & 57,7 & 11 & 42,3 & 26 & 100,0 & \\
\hline Obesitas & 5 & 11,4 & 39 & 88,6 & 44 & 100,0 & 0,000 \\
\hline Total & 20 & 28,6 & 50 & 71,4 & 70 & 100,0 & \\
\hline
\end{tabular}

Berdasarkan tabel di atas dapat dilihat bahwa responden dengan IMT tidak obesitas dan OA ringan sebanyak 15 orang $(57,7 \%)$ dan responden dengan IMT Tidak obesitas dan OA berat sebanyak 11 orang $(42,3 \%)$. Kemudian responden dengan IMT obesitas dan OA ringan sebanyak 5 orang $(11,4 \%)$ dan responden dengan IMT obesitas dan OA berat sebanyak 39 orang $(88,6 \%)$.
Untuk mengetahui hubungan antara Indeks Massa Tubuh (IMT) dengan Osteoartritis Lutut (OA) dilakukan tabulasi silang (analisis chi square) dan secara statistik menunjukkan bahwa terdapat hubungan yang bermakna antara obesitas dengan kejadian osteoartritis lutut, dengan nilai $P$ value $=0,000(P<0,05)$. 


\section{PEMBAHASAN}

Dari hasil penelitian yang dilakukan pada tanggal 22 mei - 17 juni 2020, didapatkan responden yang datang ke RSU Teungku peukan Aceh barat daya berkisar antara 28 tahun hingga 80 tahun dan terbanyak pada rentang usia 51-60 tahun sebesar $28,6 \%$ atau berjumlah 20 pasien. Hal ini sesuai dengan penelitian yang dilakukan oleh AS Nugraha, dkk (2015) di mana ratarata usia responden yang terkena Osteoartritis (OA) lutut yaitu di atas 40 tahun. Insiden OA lutut akan meningkat seiring dengan bertambahnya usia di mana terdapat peningkatan penggunaan sendi sehingga terjadi keseimbangan faktor biokimia dengan bio mekanik di mana pada usia tua terdapat perubahan fungsi kondrosit dan matriks tulang rawan sendi, sementara penggunaan sendi meningkat di samping pada usia tua sering terdapat kelemahan ligamen dan mengakibatkan penurunan kekuatan dan massa otot sekitar sendi.

Menurut jenis kelamin sebagian besar yang mengalami osteoartritis (OA) lutut yaitu perempuan sebanyak 51 orang $(72,9 \%)$ dibandingkan dengan laki-laki sebanyak 19 orang $(27,1 \%)$. Hal ini sejalan dengan teori yang ada pada Buku Ajar Ilmu Penyakit Dalam mengenai risiko OA berdasarkan jenis kelamin laki-laki lebih sedikit terkena OA dibandingkan pada wanita apa lagi pada wanita > 50 tahun (setelah menopause) hal ini juga menunjukkan adanya peran hormonal pada patogenesis OA (Kalim dkk, 2015).

Pada penelitian ini juga ditemukan pasien yang mengalami osteoartritis (OA) lutut lebih banyak terjadi pada orang yang mengalami IMT obesitas yaitu sebesar 44 orang $(62,9 \%)$ dari pada dengan IMT yang tidak obesitas sebanyak 26 orang $(37,1 \%)$. Hal ini sesuai dengan penelitian yang dilakukanoleh Nursyarifah dkk (2011) di mana kejadian OA sangat banyak ditemukan pada responden yang mengalami obesitas dibandingkan dengan yang tidak obesitas, dikarenakan salah satu terjadi OA dikarenakan berat badan yang berlebihan sehingga akan menambah beban sendi penumpu berat badan sehingga stres mekanik bertambah dan dapat mempercepat perubahan biokimia rawan sendi (degenerasi), di mana pada penelitiannya menunjukkan bahwa kenaikan Indeks massa tubuh (IMT) berhubungan dengan meningkatnya faktor risiko Osteoartritis.

Menurut hasil uji statistik pada penelitian ini dengan menggunakan uji chi square test didapatkan $P$ value $=$ $0,000(\mathrm{P}<0,05)$. Hal ini berarti $\mathrm{H}_{0}$ ditolak dan $\mathrm{H}_{\mathrm{a}}$ sehingga dapat disimpulkan terdapat hubungan bermakna antara obesitas dengan kejadian Osteoartritis (OA) lutut di RSU Teungku Peukan Aceh Barat Daya. Hasil ini sesuai dengan penelitian yang dilakukanoleh Sri Hartutik dkk (2018) dengan menggunakan korelasi kendal tau, di mana didapatkan $P$ value $=0,013<$ nilai $a(0,05)$ di mana berarti terdapat hubungan antara obesitas dengan nyeri persendian lutut pada lansia di Desa Daleman kecamatan Tulung kabupaten Klaten. Hal ini juga sesuai dengan penelitian yang dilakukan oleh Rifa Siti Nursyarifah dkk (2011) dengan menggunakan $u j i$ Kolmogorov-Smirnov didapatkan nilai significancy 0,000 . Oleh karena nilai $P<0,05$ makna yang didapatkan terdapat hubungan antara obesitas dengan kejadian osteoartritis lutut di RSUP Dr. Kariadi Semarang periode Oktober-Desember 2011. pada penelitian tersebut juga didapatkan pekerjaan responden dalam penelitian ini lebih banyak pada ibu rumah tangga (50\%) di mana banyak disebabkan oleh aktivitas yang membebani lutut dalam jangka waktu yang lama kemudian pada penelitian ini juga mendapatkan responden yang menderita $O A$ lutut baik secara unilateral maupun bilateral lebih banyak terjadi pada OA lutut ekstrim berat.

Hasil dari analisa penelitian yang dilakukan oleh A Nugraha dkk (2015) didapatkan hasil dengan menggunakan uji chi square dengan program SPSS di dapatkan hasil $P=0,001 \quad(P<0,005)$ 
yang mana berarti terdapat hubungan antara obesitas dengan osteoartritis lutut pada lansia di Laweyan Surakarta. Hasil yang sama juga terdapat pada penelitian yang dilakukan oleh Roby Arismunandar (2017) pada penelitian itu juga dikatakan terdapat hubungan obesitas dengan kejadian osteoartritis sendi lutut. Pada penelitian tersebut juga dikatakan obesitas memiliki faktor risiko 4 sampai dengan 5 kali untuk terserang Osteoartritis pada lutut dibandingkan dengan yang tidak obesitas, beratnya OA juga terdapat hubungan dengan usia, semakin tua usia maka terjadi penurunan kekuatan kolagen dan proteoglikan pada kartilago sendi.

Hasil penelitian juga menunjukkan bahwa pasien Osteoartritis tidak semua nya dalam indeks massa tubuh yang obesitas pada saat pemeriksaan, walaupun rata-rata dalam indeks massa tubuh yang obesitas, tetapi pada saat wawancara pasien juga mengungkapkan bahwa mereka dulunya lebih gemuk dari pada saat pengambilan data. Hal ini menunjukkan adanya faktor risiko lain yang dapat menyebabkan terjadinya Osteoartritis terutama sendi lutut yakni faktor risiko dari pekerjaan, usia, dan sebagainya (Kalim dkk, 2015).

\section{KESIMPULAN}

Berdasarkan hasil penelitian yang dilakukan pada pasien Obesitas dan Osteoartritis (OA) lutut di poli bedah, poli penyakit dalam, poli saraf Rumah Sakit Umum Daerah Teungku Peukan Aceh Barat Daya pada tanggal 22 juni 2020 sampai tanggal 17 Juni 2020 dapat disimpulkan bahwa terdapat hubungan antara obesitas dengan kejadian Osteoartritis (OA) lutut di RSU Teungku Peukan Aceh Barat Daya.

\section{SARAN}

Berdasarkan penelitian yang telah dilakukan peneliti mengajukan beberapa saran sebagai berikut :

1. Bagi penelitian selanjutnya diharapkan dengan mengambil priode waktu yang lebih panjang agar data sekunder yang didapatkan lebih banyak dan hasil lebih bermakna.

2. Melihat angka kejadian yang terkena Osteoartritis (OA) disertai obesitas cukup tinggi, maka sangat diharapkan kepada masyarakat mencegah faktor risikonya sedini mungkin dan mengubah gaya hidup.

\section{DAFTAR PUSTAKA}

Ali, WA. (2014).Prevalensi dan Distribusi Osteoartritis Lutut Berdasarkan Karakteristik SosioDemografi Dan Faktor Risiko di Wilayah Kerja Puskesmas Susut I Kecamatan Susut, Kabupaten Bangli Pada Tahun. Science and Technology Index. 4(1):32-41.

Arismunandar R. (2015). The Relations Between Obesity and Osteoarthritis Knee in Elderly Patients. Med J Lampung Univ4(5):110-116.

Buttgereit F, Burmester GR, Bijlsma JWJ (2015). Non-surgical

Management of Knee Osteoarthritis: where are we now and where do we need to go. RMD Open 1(1):1-5.

Dulay GS, Cooper C, Dennison EM. (2015). Knee Pain, Knee Injury, Knee Osteoarthritis \&Work.Best Pract Res Clin Rheumato/29(3):454-461.

Hartutik S. (2018). Tingkat Obesitas dengan Nyeri Persendian Lutut pada Lansia.Jurnal Ilmu Kesehatan 16(2):206-215.

Kalim $H$, Isbagio $H$, Soeroso J, dkk. (2015).Buku Ajar Ilmu Penyakit Dalam. Jakarta Pusat: Fakultas Krdokteran Universitas Indonesia.

Kulkarni K, Karssiens T, Kumar V, Pandit H. (2016). Obesity and Osteoarthritis.Maturitas 10(89):2228.

Mobasheri A, Batt M. (2016) An update on the pathophysiology of osteoarthritis. Annals of physicaal and Rehabilitation Medicine.59(56):333-339.

Nugraha AS, Widyatmoko S, Jatmiko SW. (2015). Hubungan Obesitas dengan Terjadinya Osteoartritis 
Lutut pada Lansia Kecamatan Laweyan Surakarta.Biomedika. 7(1):15-18.

Nursyarifah RS, Herlambang KS, A MT. (2012). Hubungan Antara Obesitas dengan Osteoartritis Lutut di RSUP $\mathrm{Dr}$. Kariadi Semarang Periode Oktober-Desember 2011. Jurnal Kedokteran Muhammadiyah.1(3):80-85.

Soendoro T. (2009). Riset Kesehatan Dasar (RISKESDAS).Provinsi Nanggroe Aceh Darussalam.

Sugono S. (2014)Buku Ajar Ilmu Penyakit Dalam.Jakarta Pusat: Penerbitan Ilmu Penyakit Dalam. 